\title{
CONFORMIST OR DEVIANT: CHILDREN'S CHARACTER PROBLEMS AND LOCAL CULTURE
}

\author{
HOWARD KLAPMAN, M.D.
}

AND

IKUKO MORINO, M.S.W.

\begin{abstract}
Children's Psychiatric Hospital, University of Michigan Medical Center, Ann Arbor, Michigan
\end{abstract}

\begin{abstract}
$\mathrm{T}$ HE problem of relating an emotionally ill individual and his pathological mode of adaptation as seen in the local culture is indeed fascinating. It is well known that certain cultures, such as the Hutterites, apparently tend to produce very little emotional illness, while others, such as the Kaska Indians, would appear to have a fair amount of emotional disturbance. (5) Kardiner and Ovesey discuss how cultural factors affect the standardized patterns of child-rearing in Negro culture. ${ }^{(6)}$ The Midtown Study postulates that "socio-cultural conditions operating in intrafamily and extra-family settings during childhood and adulthood have measurable consequences reflected in the mental health differences to be observed within a population". ${ }^{(10)}$
\end{abstract}

In the traditional psychotherapeutic approach, the therapist served as a "blank screen", and the therapist's observation of a patient was limited to the patient's intrapsychic conflicts. It was therefore extremely difficult to study the patient in his cultural milieu. With the development of ego psychology, which emphasizes interpersonal relationships, however, attempts to integrate culture and personality have become possible. Other developments of particular importance are the use of the social rôle concept, as well as studies in the area of non-verbal communication and transaction. Until these observations were made, it was difficult to study interaction within a culture because, until the observer could interpret signals sent out by the subject in terms of their effect on himself, he could not attempt to interpret the effect of these signals sent out by various members of a culture on each other.

This paper deals with impressions received on several school visits made to local communities just prior to or following the discharge from a children's psychiatric ward of children who had been treated for emotional problems involving, among other things, characterological disturbance. On these visits we reached several conclusions which broadened our view of the patients and their families.

The first case is that of Jerry. Jerry was a thirteen-year-old boy who was excessively competitive, to the extent that he would withdraw from competition rather than lose. Prior to admission, he had resided in a suburb of one of America's largest cities. The suburb is inhabited primarily by Jewish families, such as Jerry's, who had moved from the city. Because of their ethnic background, these people were restricted from many of the choice suburbs and accordingly were determined to make theirs the best suburb possible. Their public agencies, such as the police, were the finest. Competition was stressed in both school and financial matters. On the school visit it was noted that all the officials were dressed very neatly. The assistant principal, who did not belong to the ethnic group of 
the community, boasted that they had the second highest scholastic average for junior high schools in the state. He attempted to dissociate himself from the community to some extent by stating that this aggressiveness was a problem they had with their students. On the surface everything was quite neat and orderly; yet one felt aggressiveness and competitiveness in the interaction of officials as well as in their attitude towards us, the visitors from the local university hospital. It was our feeling at the time that there was a correlation between Jerry's mode of adaptation and that of the community. Yet we called Jerry's mode of adaptation pathological, and indeed he was in the hospital partly to receive help to change this. We wondered if, as we helped him to change, we might be hampering his potential adjustment in his local community to some extent.

The next case is Will, also thirteen years old. Will, who was severely disturbed, came from Industryville, a town in which most of the members of the community worked for the one major industry of the town. This industry is highly technical and many of the people in town, including Will's father, are professionals. There is a fair amount of uniformity in the town and the people are definitely aware of where they stand in the hierarchy. People from professional families are high in the hierarchy and are quite proud. Will feels that he is better than others. He is compulsive and dogmatically orders his universe. While Will had other causes for his condition, one could see during the school visit that the social factors of Industryville (i.e. the existence of the rigid hierarchical system and the fact that Will's family belonged to its upper segment) might somewhat account for his condition. Also, we learned one other rather significant thing. Will and his family were generally regarded by the town as perfect, but after his "alma mater" beat Industryville's favourite college football team, Will's father put out a sign in front of his house declaring this fact. This was looked upon as quite peculiar by Industryville people. From this one might conclude that even though the disturbed person or family may take on community modes of adaptation, they may not do so as insiders.

This pattern of surface adherence to rules, combined with an obvious social withdrawal in at least one area, could be seen in several other families. In, for instance, the case of John, nine years old, both the child and family tried very hard to keep up with an upward-striving middle-class suburban area. This resulted in the family members putting stress on, among other things, cleanliness and joining activities. Yet, despite this, the family tended to withdraw from others at times and John carried on his revolt by being encopretic.

Another case is that of Dale, who resides in Vacationville. When Dale first came to the psychiatric ward, he was severely depressed and paranoid, and seemed to feel inadequate. It was readily noted both in the history and in observing Dale's ward behaviour that he would attack others in a "sneaky" way. For example, he would wait until everyone would be watching television and then would begin to hum. The most striking fact was that for the most part, even when he was acting up, Dale was extremely likeable. He was an extremely clean child, and he had a very "sweet" smile. By and large, the child would not openly resist an order by a ward staff. In fact, he would usually smile and obey.

Dale was the eighth of nine children. It appeared, in interviewing the family, that all of them, including the parents, felt inadequate. There was a paranoid and depressive quality about the entire family. They seemed to maintain a conspiracy 
of silence in the fear that if others knew of their true feelings, they would not be liked. In the ten months of intensive treatment with Dale's family, we had to deal with their fear that our primary interest was not in the welfare of Dale, but in research or experimentation. The father even sent us a magazine article which stated that nowadays even dogs need psychiatrists. Following this incident, the family became involved in psychiatric treatment.

Later the father admitted that their family interaction was based on "peace at any cost". Negative feelings were totally denied, and problem areas were sealed off. They felt that everybody in town knew about Dale's hospitalization and the severity of his illness, and that they talked about him and his family. Father was a vice-president of a firm. He expressed his low self-concept very clearly when he, jokingly, asked if we might have a job for him as a janitor in the hospital so that he would be near his son. Mother was much more difficult to reach in therapy, but it was obvious that for some reason she, too, was instrumental in maintaining the conspiracy of silence.

Many of the modes of adaptation seen in Dale and his family were also seen in the community, located in a region once thickly covered with pine and hardwood forests. Since the late nineteenth century when these were cut down, the inhabitants have derived a livelihood from the soil. In recent years, it relies for its subsistence chiefly on summer vacation trade. In this part of the state are hundreds of lakes and streams. Vacationville is the metropolis of Big Bay. It is surrounded by rolling farmlands and patches of forests, which overlook the city and the blue waters. Its summer activity reaches a peak during July and August. Each year the city also sponsors the Vacationville Winter Festival.

The town of Vacationville triples its population during the summer months. A high percentage of the vacationers are wealthy people from large cities who own their own homes in Vacationville. These people have brought in much of their own culture and have greatly influenced the lives of the natives. For example, they have brought in fashionable shops, which are open only in the summer. Vacationville has eating places far more cosmopolitan than those of her neighbouring towns, and her people dress in city clothes to a fair degree. They are, as one native puts it, "citified". However, it was quite difficult to get Vacationville people actually to express pride in their town. Despite the fact that it is a beautiful place, if you mention it the answer will frequently be that it does have rich residents, but that the rich residents are gone in the winter, or that the people come up here only to ski. All in all, there seemed to be a general feeling of inadequacy in the town. Even though they had some of the advantages of the city, wore city clothes and even had adequate incomes, they felt that they were missing a great deal of the culture of the outside.

A major factor was that the outsider comes to Vacationville to regress and frequently do things that he would not do at home. This, in a sense, is encouraged by the local people who serve the wealthy.

Because many of the vacationers are permanent summer residents, they, too, belong to Vacationville, and feeling between the vacationers and the natives can be complex. The natives cannot frankly take advantage of vacationers, since they will be coming back the following year. Hostility expressed towards the outsider is subtle and often the measures used were those of sabotage. Any outsider is 
viewed as an invader, who is there to enjoy himself and probably to take advantage of Vacationville. Where two cultures come into contact, stress is felt. People who have been socialized in one tradition interact with representatives of a different way of life. Often the invading group fails to understand the values and expectations of its hosts. When the invaders come with high prestige, the natives may try to imitate the customs of the invaders. Then, the natives begin to question the old customs and behaviour. The dominant group's culture pattern, i.e. that of the vacationers, forced the native culture to bear a larger share of stress. School personnel first welcomed us with hospitality, then expressed their defensiveness, hostility and mistrust of us.

A native mentioned that the city had a concert series of four programmes a season. Other conversation concerning cultural opportunities indicated that they valued these very highly and were quite defensive of the limited cultural opportunities in their town. We were told that there were twenty-two churches in Vacationville, predominantly of strict and fundamental denominations of Protestantism. These also serve as centres of social activities for many natives.

The lobby and the dining-room of the hotel were both furnished in good taste, and comfortably heated. It compared quite favourably to hotels in other cities. However, the rooms were very old-fashioned, overheated and uncomfortable, impossible to cool off. We felt this as a retaliation by the natives to those outsiders who talked of how cold it was in Vacationville. The keys to the rooms were skeleton keys so that one key fits any room. If a theft occurs in a room, the hotel management can claim that they were not responsible for valuables left in the room and not checked at the desk. We felt the skeleton key phenomenon symbolized the natives' desire to sabotage against the outsiders. Superficially, they give us a key, a measure of security, which actually is worthless since all others have essentially the same key. Therefore, it is a double fallacy.

On the second day, as were were ready to head back, the car did not start. The garage men came promptly and pushed our car into the garage. The heavy accumulation of snow was not cleaned off in front of the garage. We did not have snow tyres on the car. After having started the engine for us, they told us how to get out of the driveway, but would not get the car out of the snow for us. We got stuck in this deep snow several times before we were able finally to get back on the street. We had to stop and ask for directions to get back to the U.S. highway. A native first gave us the directions which involved our making a U-turn and climbing a snow-covered icy road, uphill. When we asked for an easier way to get to the highway, he immediately gave it to us. It was just around the corner. As we drove away, we remembered a painting which hung in the hotel. It pictured seductive girls at a pier embracing sailors as a boat is entering. This seemed to symbolize Vacationville. Thus, the social environment was intensely related to the intrapsychic problems of the members.

Let us now turn to Dale's family. A local medical doctor informed us that the family is a very close-knit one, and the mother seems over-protective of the children. Once when Dale's sister, a senior in high school, was to baby-sit, her mother came instead, stating that her daughter was ill. Any other baby-sitter would have called and cancelled. All children in Vacationville play outside on Saturday afternoon. Dale's mother calls her children in at 4 p.m. on Saturdays to take their baths. Before we paid this visit to the community, we felt these 
actions on the part of the mother were indications of her unwillingness to let her children grow up. On visiting Dale's home, we gained additional insights. The mother, who was brought up in an urban area, seemed unhappy in Vacationville. She made several comments, indicating that it was small, and giggled about it. She laughed uncomfortably as she pointed out to us the small volume of their local paper. By pulling her children closer to her, she keeps her children "different" from the natives. School personnel repeatedly pointed out that Dale's family would not send their children to free swimming lessons in the summer or to free skiing lessons in the winter, although all the other children took part in these.

In general, we see that there is a definite relationship between culture and psychopathology. Man expresses and channels his drives through culture. His individual repertory of behaviour is drawn from the various modes available within the culture in which he resides.

In all the cases that we have discussed, we saw a definite relationship between the local culture and the individual's psychopathology. In three of them, the manifestation of the individual's psychopathology appeared to be similar to the cultural mode of adaptation. In one, the symptomatology was an obvious manifestation of rebellion.

The question we asked was whether or not all four of the children and their families were actually deviants from their local cultures. The fact that Dale's family were deviants was readily seen in the mother's systematic withdrawal of her children from the community, and the fact that the various town people regarded this as unusual and bad. We therefore postulate a vicious cycle. Because of their own intrapsychic and intrafamilial problems, the members of Dale's family felt that they did not belong and had, therefore, identity problems. They acted them out by taking on aspects of the typical community mode of adaptation. They were superficially very nice to people and, as was typical in the culture, subtly sabotaged them. However, they missed the more subtle point - that although one may sabotage the outsider, one should do certain things in order to become part of the in-group, such as having the children take ski lessons and go to the beach. By not doing so, one becomes identified by the community as deviant.

This case is similar to that of Will's father, who understood the hierarchy of Industryville, but hung up a sign against the local football team, an almost unthinkable crime. Being classed as a deviant, then, reinforces the feeling of not belonging, and the cycle turns again.

Next, consider the concept of a sick society, as seen in the case of Vacationville. Some societies, according to Fromm, cannot tolerate individualization. (3) The natives of Vacationville felt they were in a most unfortunate position. They were the keepers of an area where the wealthy people who owned the homes there would come to do things which they would not do in their respectable homes. This, in itself, offended the old rural background of the town. The fact that the natives had taken on to some extent the wealthy culture, of which they felt they were only given part, added to their feeling of misfortune. Perhaps the most crushing fact was that they accepted money to permit this vice in their town, and had to live in their town during the off-season so that the masters could return for their pleasure. 
The fact that Vacationville gives pleasure for money is a highly important issue. Choisy states: "Prostitution starts the moment the giver of sexual pleasure becomes a seller. Money is heavily loaded with all kinds of psychological conflicts. In our civilization, among other things (what Freud calls the anal manifestation), it symbolizes the will to power and the ensuing unconscious guilt of having taken the father's place."(2) In a sense, Vacationville, owned by the wealthy masters, is a mistress community. It is obvious that rather desperate repression and suppression is used there. This cultural adaptation is seen in the large number of fundamentalist churches. The rigid standards used by these churches certainly de-emphasize individuation. In a culture with more rigid standards, one would expect more deviants. The question that one must ask is whether these deviants are to be considered mentally ill. This certainly would depend on how the community would define the deviant, be he called patient, criminal, heretic, etc. In some rather intellectual communities, the person who does not profess himself to be neurotic may be deviant. Certainly separating deviance and mental illness in each culture is crucial to understanding the problems of the community, as well as those of the individuals residing there.

These observations just barely scratch the surface of a field that needs further exploration. Whereas originally it was considered adequate to deal only with the patient and his intrapsychic conflicts, it later became evident that it was important to deal with the patient's interpersonal adjustment, including his family. More and more we are beginning to realize that we must also understand the community as a whole.

\section{REFERENCES}

1. American Guild Series (sponsored by the Michigan State Administrative Board). Michigan: $A$ Guide to the Wolverine State. New York: Oxford University Press, 1941.

2. Choisy, M.: Psychoanalysis of the Prostitute. New York: Philosophical Library, 1961.

3. Fromm, E.: Escape from Freedom. New York: Rinehart \& Co., 1941.

4. Grinker, R., MacGregor, H., Selan, K., Arnett, K., and Kohrman, J.: Psychiatric Social Work: A Transactional Care Book. New York: Basic Books Inc., 1961.

5. Honigmann, J.: Culture and Personality. New York: Harper \& Bros., Publishers, 1954.

6. Kardiner, A., and Ovesey, L.: The Mark of Oppression. New York: W. W. Norton \& Co., 1951.

7. Opler, M. K.: "Cultural anthropology and social psychiatry." American Journal of Psychiatry, 1956, vol. 113, 302-311.

8. Pollak, O.: Integrating Sociological and Psychoanalytic Concepts: An Exploration in Child Psychotherapy. New York: Russell Sage Foundation, 1956.

9. Rennie, T. A. C., Srole, L., Opler, M. K., and Langner, T. S.: "Urban life and mental health: socio-economic status and mental disorder in the metropolis." American Journal of Psychiatry, 1957, 831-836.

10. Srole, S., Langner, T. S., Michael, S. T., Opler, M. K., and Rennie, T. A. C.: Mental Health in the Metropolis: The Midtown Manhattan Study. Vol. I. New York: McGrawHill Book Co. Inc., 1962. 